\title{
The influence of tin doping on the structural \& morphology features of indium oxide
}

\author{
A.H. Sofi, F.A. Dar, S. A. Akhoon and M. A. Shah* \\ Department of Physics, NIT-Srinagar, J\&K, India-190006 \\ Email:shah@nitsri.net
}

Indium oxide $\left(\operatorname{In}_{2} \mathrm{O}_{3}\right)$, a wide band gap $(\sim 3.6$ $\mathrm{eV})$ transparent conducting oxide is of great interest. Its unusual combination of high transparency in the visible range and high electrical conductivity (free carriers up to $10^{17}$ to $10^{19} \mathrm{~cm}^{-3}$ ) gives it wide device applicability [1-3]. Various methods have been reported for the synthesis of $\operatorname{In}_{2} \mathrm{O}_{3}$ nanostructures. However, we have employed a catalyst and surfactant free approach for the synthesis of indium-tin oxide nanostructures at very low temperature. The approach is based on a simple reaction of ITO powder and de-ionized water at $190{ }^{\circ} \mathrm{C}$. The synthesized samples were characterized by Powder X-ray diffraction technique and Scanning electron microscopy (SEM) to study the structural and the morphological features. Figure 1 and Figure 2 show the SEM images of the ITO nanostructures. Further, the reported method besides being catalyst free is economical, fast and environmental friendly, which will make it suitable for large-scale production.

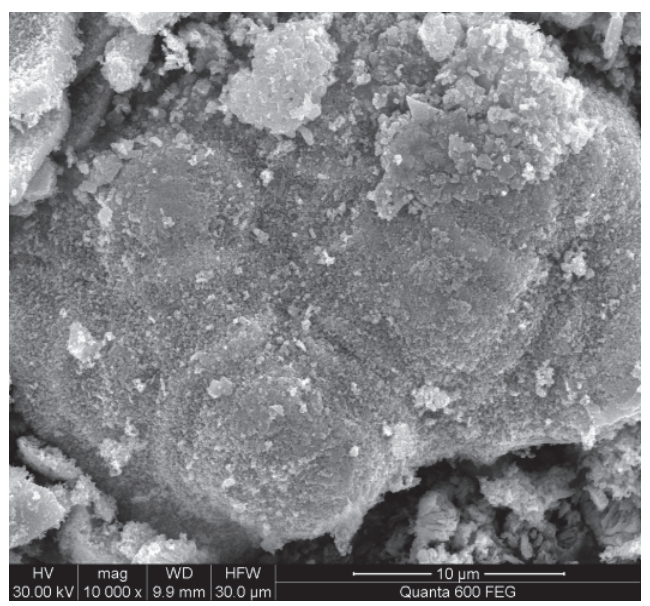

Figure 1: SEM image of ITO nanostructures

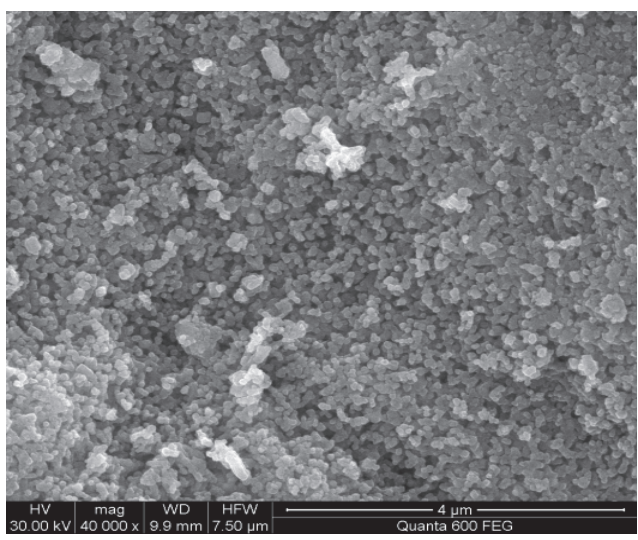

Figure 2: Magnified SEM image ITO nanostructures

Keywords: soft synthesis; spherical nanoparticles; formation mechanism

\section{References}

1. Dawar, A. L., Jain, A. K., \& Jagadish, C. (1995). Semiconducting transparent thin films (p. 181). Bristol, UK, Philadelphia, PA: Institute of Physics Publication.

2. Tahar, R. B. H., Ban, T., Ohya, Y., \& Takahashi, Y. (1998). Tin doped indium oxide thin films: Electrical properties. Journal of Applied Physics,83(5), 2631-2645.

3. Sofi, A. H., \& Shah, M. A. (2014). The study of the structural and morphology features of indium tin oxide (ITO) nanostructures. Materials Research Express, 1(1), 015041. 